\title{
STABILISASI SISTEM LINIER POSITIF MENGGUNAKAN STATE FEEDBACK
}

\author{
ERIN DWI FENTIKA, ZULAKMAL \\ Program Studi Matematika, \\ Fakultas Matematika dan Ilmu Pengetahuan Alam, Universitas Andalas, \\ Kampus UNAND Limau Manis Padang, Indonesia, \\ email: erinfentika@gmail.com
}

\begin{abstract}
Dalam makalah ini dikaji proses menstabilkan suatu sistem linier positif menggunakan state feedback. Suatu sistem linier dikatakan dapat distabilkan jika terdapat kontrol $\mathbf{u}=-K_{s} \mathbf{x}$, untuk suatu matriks $K_{s}$ sedemikian sehingga sistem $\dot{\mathbf{x}}=\left(A-B K_{s}\right) \mathbf{x}$ adalah stabil, artinya matriks $K_{s}$ dipilih sedemikian sehingga bagian riil dari semua nilai eigen matriks $A-B K_{s}$ adalah negatif.

Kata Kunci: State feedback, kestabilan sistem, positif, nilai eigen
\end{abstract}

\section{PENDAHULUAN}

Diberikan sistem kontrol linier sebagai berikut:

$$
\dot{\mathbf{x}}=A \mathbf{x}+B \mathbf{u}, \mathbf{x}(0)=\mathbf{x}_{0},
$$

dimana $A \in \mathbb{R}^{n \times n}, B \in \mathbb{R}^{n \times m}$. Jika matriks $A$ dan $B$ bergantung terhadap waktu, maka sistem (1.1) disebut sistem kontrol linier time varying.

Sistem (1.1) dikatakan positif jika untuk setiap $\mathbf{u} \in \mathbb{R}_{+}^{m}$ dan untuk setiap $\mathbf{x}_{0} \in$ $\mathbb{R}_{+}^{n}$ dan $t \geq 0$, maka $\mathbf{x}(t) \in \mathbb{R}_{+}^{n}$. Dalam [3] dinyatakan bahwa sistem (1.1) adalah positif jika dan hanya jika $A$ adalah suatu matriks Metzler, yaitu $a_{i j} \geq 0$ untuk setiap $i \neq j, i, j=1,2, \cdots, n$ dan $B \in \mathbb{R}_{+}^{n \times m}$.

Salah satu kajian dalam sistem kontrol adalah mengenai kestabilan sistem tersebut. Sistem (1.1) dikatakan stabil jika $t \rightarrow \infty$ mengakibatkan $\mathbf{x}(t) \rightarrow 0$. Salah satu kriteria untuk menentukan kestabilan sistem (1.1) adalah kriteria nilai eigen. Sistem (1.1) adalah stabil jika bagian riil dari semua nilai eigen matriks $A$ adalah negatif. Dengan demikian, sistem (1.1) adalah positif dan stabil jika $A$ adalah Metzler, $B \in \mathbb{R}_{+}^{n \times m}$ dan bagian riil dari semua nilai eigen matriks $A$ adalah negatif.

Sistem (1.1) yang tidak stabil dikatakan dapat distabilkan jika terdapat kontrol $\mathbf{u}=-K_{s} \mathbf{x}$ untuk suatu $K_{s} \in \mathbb{R}^{m \times n}$ sedemikian sehingga sistem

$$
\dot{\mathbf{x}}=\left(A-B K_{s}\right) \mathbf{x}
$$

adalah stabil, artinya matriks $K_{s}$ dipilih sedemikian sehingga bagian riil dari semua nilai eigen matriks $A-B K_{s}$ adalah negatif. Matriks $K_{s}$ disebut matriks feedback dan vektor $\mathbf{u}$ dikatakan kontrol yang menstabilkan sistem (1.1). Dalam makalah ini dikaji syarat untuk matriks $K_{s} \in \mathbb{R}^{1 \times n}$ sedemikian sehingga sistem (1.2) adalah positif dan stabil. 


\section{Pembahasan}

Lema berikut diperlukan untuk membuktikan hasil utama.

Lema 2.1. [2] Suatu matriks Metzler $A \in \mathbb{R}^{n \times n}$ adalah stabil jika dan hanya jika

$$
\exists \boldsymbol{d} \in \operatorname{int}\left(\mathbb{R}_{+}^{n}\right) \text { sedemikian sehingga } A \boldsymbol{d} \in \operatorname{int}\left(\mathbb{R}_{+}^{n}\right) .
$$

Selain itu, jika A stabil maka setiap submatriks utama dari A juga stabil.

Lema 2.2. [2] Tidak ada $K_{s} \in \mathbb{R}_{-}^{1 \times n}$ sedemikian sehingga sistem positif dengan input tunggal yang tidak stabil (1.1) dapat distabilkan.

Bukti. Misalkan ada $K_{s} \in \mathbb{R}_{-}^{1 \times n}$ sedemikian sehingga sistem positif dengan input tunggal yang tidak stabil (1.1) dapat distabilkan, maka $\left(A-B K_{s}\right)$ adalah matriks Metzler stabil. Jelas bahwa $-B K_{s} \in \mathbb{R}_{+}^{n \times n}$, dan notasikan $-B K_{s}=A^{+}=$ $\left[a_{i j}^{+}\right], i, j=1,2, \cdots, n$. Berdasarkan Lema 2.1, terdapat

$$
\mathbf{d}=\left[\begin{array}{llll}
d_{1} & d_{2} & \cdots & d_{n}
\end{array}\right]^{T} \in \operatorname{int}\left(\mathbb{R}_{+}^{n}\right)
$$

sedemikian sehingga $-\left(A+A^{+}\right) \mathbf{d} \in \operatorname{int}\left(\mathbb{R}_{+}^{n}\right)$, yaitu

$$
\begin{aligned}
0 & <-d_{1} a_{i 1}-\cdots-d_{n} a_{i n}-d_{1} a_{i 1}^{+}-\cdots-d_{n} a_{i n}^{+}, \\
& \leq-d_{1} a_{i 1}-\cdots-d_{n} a_{i n}, \forall_{i}=1, \cdots, n .
\end{aligned}
$$

Tetapi, karena $A$ tidak stabil maka berdasarkan Lema 2.1, untuk setiap $d \in \operatorname{int}\left(\mathbb{R}_{+}^{n}\right)$ terdapat suatu $i$ sedemikian sehingga $-d_{1} a_{i 1}-\cdots d_{n} a_{i n} \leq 0$ yang bertentangan dengan (2.1).

Teorema 2.3. [2] Misalkan sistem (1.1) adalah positif dan

$$
K_{s}=\left[k_{s}^{(1)} k_{s}^{(2)} \cdots k_{s}^{(n)}\right] \in \mathbb{R}_{+}^{1 \times n}
$$

didefinisikan sebagai berikut:

$$
\begin{aligned}
& k_{s}^{(i)}>\frac{a_{i i}}{b_{i}}, \text { jika } b_{j}=0, \forall j \neq i, \\
& k_{s}^{(i)}=\min _{j \neq i, b_{j} \neq 0}\left\{\frac{a_{j i}}{b_{j}}\right\}, \text { untuk hal lainnya, }
\end{aligned}
$$

untuk $i, j \in\{1,2, \cdots, n\}$. Jika $b_{i} \neq 0$ dan $b_{j}=0$ untuk setiap $j \neq i, j, i \in$ $\{1, \cdots, n\}$, maka $K_{s}$ yang didefinisikan dalam (2.4) membuat matriks $A-B K_{s}$ menjadi matriks Metzler stabil jika dan hanya jika submatriks $A^{(i)}$ adalah stabil.

Bukti. Tanpa mengurangi keumuman, asumsikan bahwa $b_{1} \neq 0$.

$(\Rightarrow)$ Misalkan terdapat suatu $K_{s} \in \mathbb{R}_{+}^{1 \times n}$ sedemikian sehingga $A-B K_{s}$ adalah suatu matriks Metzler stabil, maka submatriks $\left(A-B K_{s}\right)^{(1)}$ dan $A^{(1)}$ adalah sama, dan berdasarkan Lema 2.1 mestilah $A^{(1)}$ stabil.

$(\Leftarrow)$ Misalkan submatriks $A^{(1)}$ adalah stabil, maka berdasarkan Lema 2.1 terdapat

$$
\mathbf{d}^{\prime}=\left[d_{2} \cdots d_{n}\right] \in \operatorname{int}\left(\mathbb{R}_{+}^{n-1}\right)
$$


sedemikian sehingga

$$
-A^{1} \mathbf{d}^{\prime} \in \operatorname{int}\left(\mathbb{R}_{+}^{n-1}\right)
$$

yaitu untuk suatu $\delta_{j}>0, j \in\{2, \cdots, n\}$ berlaku

$$
-\left(a_{j 2} d_{2}+a_{j 3} d_{3}+\cdots+a_{j n} d_{n}\right)>\delta_{j} .
$$

Misalkan $\delta=\min _{i=2, \cdots, n}\left\{\delta_{j}\right\}$ dan $a=\max _{j=2, \cdots, n}\left\{a_{j 1}\right\}$. Selanjutnya, jika $a=0$, maka pilih $d_{1}=1$; dan jika $a \neq 0$, maka pilih $d_{1} \in\left(0, \frac{\delta}{a}\right)$. Dengan pilihan ini, maka $(2.1)$ terpenuhi untuk baris $2, \cdots, n$. Dengan pemilihan $d_{1}$ ini dan $k_{s}^{i}=0$ untuk $i \neq 1$ diperoleh

$$
\begin{gathered}
-\left(a_{11}-k_{s}^{1} b_{1}\right) d_{1}-\left(a_{12} d_{2}+\cdots+a_{1 n} d_{n}\right) \geqslant \\
k_{s}^{1} b_{1} d_{1}-\left(\left|a_{11}\right| d_{1}+a_{12} d_{2}+\cdots+a_{1 n} d_{n}\right)>0
\end{gathered}
$$

sehingga

$$
k_{s}^{1}>\frac{\left|a_{11}\right| d_{1}+a_{12} d_{2}+\cdots+a_{1 n} d_{n}}{b_{1} d_{1}} \geqslant 0
$$

dan

$$
k_{s}^{i}=0, i=2, \cdots, n .
$$

yang memberikan hasil yang diinginkan, yaitu

$$
-\left(a_{11}-k_{s}^{1} b_{1}\right) d_{1}-\left(a_{12} d_{2}+\cdots+a_{1 n} d_{n}\right)>0
$$

Berikut ini akan diberikan beberapa contoh yang mengilustrasikan Teorema 2.3.

Contoh 2.4. Selidiki apakah sistem linier positif berikut dapat distabilkan atau tidak.

$$
\left[\begin{array}{l}
\dot{x_{1}} \\
\dot{x_{2}} \\
\dot{x_{3}}
\end{array}\right]=\left[\begin{array}{ccc}
-1 & 2 & 1 \\
0 & -1 & 1 \\
2 & 1 & 0,5
\end{array}\right]\left[\begin{array}{l}
x_{1} \\
x_{2} \\
x_{3}
\end{array}\right]+\left[\begin{array}{l}
0 \\
0 \\
1
\end{array}\right] \boldsymbol{u} .
$$

Misalkan $K_{s}=\left[k_{s}^{1} k_{s}^{2} k_{s}^{3}\right]$. Dari persamaan (2.5) terlihat bahwa $b_{1}=b_{2}=0$. Untuk $i=1$,

$$
k_{s}^{1}=\min _{j \neq 1, b_{j} \neq 0}\left\{\frac{a_{31}}{b_{3}}\right\}=2 .
$$

Untuk $i=2$,

$$
k_{s}^{2}=\min _{j \neq 2, b_{j} \neq 0}\left\{\frac{a_{32}}{b_{3}}\right\}=1 .
$$

Untuk $i=3$,

$$
\begin{gathered}
k_{s}^{3}>\frac{a_{33}}{b_{3}} \\
k_{s}^{3}>0,5 \\
\text { pilih } k_{s}^{3}=1 .
\end{gathered}
$$


Sehingga $K_{s}=\left[\begin{array}{lll}2 & 1 & 1\end{array}\right]$. Karena $A^{(3)}=\left[\begin{array}{cc}-1 & 2 \\ 0 & -1\end{array}\right]$ adalah stabil, maka berdasarkan Teorema 2.3,

$$
A-B K_{s}=\left[\begin{array}{ccc}
-1 & 2 & 1 \\
0 & -1 & 1 \\
2 & 1 & 0,5
\end{array}\right]-\left[\begin{array}{l}
0 \\
0 \\
1
\end{array}\right]\left[\begin{array}{lll}
2 & 1 & 1
\end{array}\right]=\left[\begin{array}{ccc}
-1 & 2 & 1 \\
0 & -1 & 1 \\
0 & 0 & -0,5
\end{array}\right]
$$

merupakan matriks Metzler stabil dengan nilai-nilai eigen $-1,-1,-0,5$. Jadi sistem tersebut dapat distabilkan. Amati bahwa submatriks $(A-B K)^{(3)}=A^{(3)}$.

Contoh 2.5. Selidiki apakah sistem linier positif berikut dapat distabilkan atau tidak.

$$
\left[\begin{array}{c}
\dot{x_{1}} \\
\dot{x_{2}} \\
\dot{x_{3}} \\
\dot{x_{4}}
\end{array}\right]=\left[\begin{array}{cccc}
-3 & 1 & 1 & 2 \\
1 & -2 & 2 & 0 \\
2 & 1 & 1 & 1 \\
0 & 2 & 0 & -1
\end{array}\right]\left[\begin{array}{l}
x_{1} \\
x_{2} \\
x_{3} \\
x_{4}
\end{array}\right]+\left[\begin{array}{l}
0 \\
0 \\
2 \\
0
\end{array}\right] \boldsymbol{u}
$$

Misalkan $K_{s}=\left[k_{s}^{1} k_{s}^{2} k_{s}^{3} k_{s}^{4}\right]$. Dari persamaan (2.6) terlihat bahwa $b_{1}=b_{2}=$ $b_{4}=0$.

Untuk $i=1$,

$$
k_{s}^{1}=\min _{j \neq 1, b_{j} \neq 0}\left\{\frac{a_{31}}{b_{3}}\right\}=1 .
$$

Untuk $i=2$,

$$
k_{s}^{2}=\min _{j \neq 2, b_{j} \neq 0}\left\{\frac{a_{32}}{b_{3}}\right\}=\frac{1}{2} .
$$

Untuk $i=3$,

$$
\begin{gathered}
k_{s}^{3}>\frac{a_{33}}{b_{3}} \\
k_{s}^{3}>0,5 \\
\text { pilih } k_{s}^{3}=1 .
\end{gathered}
$$

Untuk $i=4$,

$$
k_{s}^{4}=\min _{j \neq 4, b_{j} \neq 0}\left\{\frac{a_{34}}{b_{3}}\right\}=\frac{1}{2}
$$

Sehingga $K_{s}=\left[1 \frac{1}{2} 1 \frac{1}{2}\right]$. Karena $A^{(3)}=\left[\begin{array}{ccc}-3 & 1 & 2 \\ 1 & -2 & 0 \\ 0 & 2 & -1\end{array}\right]$ adalah stabil, maka berdasarkan Teorema 2.3,

$$
A-B K_{s}=\left[\begin{array}{cccc}
-3 & 1 & 1 & 2 \\
1 & -2 & 2 & 0 \\
2 & 1 & 1 & 1 \\
0 & 2 & 0 & -1
\end{array}\right]-\left[\begin{array}{l}
0 \\
0 \\
2 \\
0
\end{array}\right]\left[\begin{array}{llll}
1 & \frac{1}{2} & 1 & \frac{1}{2}
\end{array}\right]=\left[\begin{array}{cccc}
-3 & 1 & 1 & 2 \\
1 & -2 & 2 & 0 \\
0 & 0 & -1 & 0 \\
0 & 2 & 0 & -1
\end{array}\right]
$$

merupakan matriks Metzler stabil dengan nilai-nilai eigen $-2.9466+0.8297 i$, $-2.9466-0.8297 i,-0.1067,-1.0000$. Jadi sistem tersebut dapat distabilkan. Amati bahwa submatriks $(A-B K)^{(3)}=A^{(3)}$. 


\section{Kesimpulan}

Misalkan matriks

$$
K_{s}=\left[k_{s}^{(1)} k^{(2)} \cdots k_{s}^{(n)}\right] \in \mathbb{R}_{+}^{1 \times n}
$$

didefinisikan sebagai berikut.

$$
\begin{aligned}
& k_{s}^{(i)}>\frac{a_{i i}}{b_{i}}, \text { jika } b_{j}=0, \forall j \neq i \\
& k_{s}^{(i)}=\min _{j \neq i, b_{j} \neq 0}\left\{\frac{a_{j i}}{b_{j}}\right\}, \text { untuk hal lainnya, }
\end{aligned}
$$

dengan $i, j \in\{1,2, \cdots, n\}$. Jika sistem (1.1) adalah positif dan $b_{i} \neq 0$ dan $b_{j}=0$ untuk setiap $j \neq i, j, i \in\{1, \cdots, n\}$, maka $K_{s}$ yang didefinisikan dalam (3.1) membuat matriks $A-B K_{s}$ menjadi matriks Metzler stabil jika dan hanya jika submatriks $A^{(i)}$ adalah stabil.

\section{Daftar Pustaka}

[1] D. Luenburger. 1979. Introduction to Dynamic System: Theory, Models and Aplication. Wiley. New York

[2] Davison, E. J. dan Roszak, B. 2009. Necessary and Sufficient Condition for Stability of Positive LTI Systems. $2^{\text {nd }}$ edition. New York: McGraw-Hill

[3] Farina, L. dan Rinaldi, S. 2000. Positive Linear Systems : Theory and Aplications. Wiley. New York

[4] Kaczorek, T. 2001. Positive 1D and 2D Systems Metzler Matrices. SpringerVerlag Berlin Heidelberg 